\title{
A LEI DO ANTITERRORISMO NA FRANÇA E A ANTÍTESE ENTRE A DEFESA DOS DIREITOS HUMANOS E A PERMISSÃO AOS ABUSOS CONTRA ELES
}

\section{Antônia Morgana Coelho Ferreira}

Pós-graduanda em Direito e Processo do Trabalho pelo Curso Prof. Jorge Hélio. Advogada.

delegada_uniforx@hotmail.com

\section{Saulo Nunes de Carvalho Almeida}

Pós-graduando em Direito do Trabalho, Tributário e Previdenciário pela Faculdade Ateneu.

saulonunes@hotmail.com

Sumário: Introdução. 1) A França como berço dos direitos humanos e os avanços nessa seara na óptica internacional. 2) $\mathrm{O}$ ataque a Paris em 2004 e o terrorismo sob uma nova perspectiva na França. 3) Legislação francesa: combate ao terrorismo ou aos direitos fundamentais? 4) Uma análise jurídico-penal da legislação francesa de combate ao terrorismo e dos princípios por ela violados. 5) O combate ao terrorismo no Brasil: anteprojetos

Resumo: O presente trabalho tem por escopo analisar a Legislação de antiterrorismo existente na França, traçando um paralelo entre essa legislação e os princípios fundamentais por ela violados, levando em consideração o fato de ser a França considerada o berço dos direitos humanos mundiais. Tentar-se-á explicar como uma civilização tão desenvolvida, que possui entre suas maiores contribuições mundiais a Declaração de Diretos do Homem e do Cidadão, de 1789, pôde desenvolver uma legislação de antiterrorismo que agride sobremaneira esses mesmos direitos humanos, tão defendidos e difundidos ao longo dos anos. Por outro lado, será traçado um panorama comparativo entre a lei de antiterrorismo francesa e a legislação existente no Brasil.

Palavras-chave: Lei de Antiterrorismo Francesa. Direitos Humanos. Legislação de Antiterrorismo Brasileira. 


\section{INTRODUÇÃO}

O corrente ano de 2009 é o ano da França no Brasil, em respeito ao ano de 2005, ano do Brasil na França, em uma política de amizade entre esses países, ambos árduos defensores dos direitos humanos no Mundo. A França com sua Declaração dos Direitos do Homem e do Cidadão, de 1789 e o Brasil com a Constituição Federal de 1988, considerada uma das mais democráticas do mundo.

Portanto, imperativo se faz um estudo sobre a França no Brasil e não apenas isso, mas sobre essa civilização em todo o mundo, explorando de forma peculiar os avanços que ela empreendeu, já durante a Revolução Francesa, no que concerne à proteção dos direitos humanos e a influência que a Declaração dos Direitos do Homem e do Cidadão teve em todo o mundo.

Para isso será analisada a Lei de Antiterrorismo francesa, considerada uma das mais severas do mundo, no que pertine à desobediência dos direitos humanos, que esse país tanto defende, e os abusos que se permite cometer para enfrentar o terrorismo, mazela que atinge diversos países do mundo, principalmente aqueles mais desenvolvidos.

O terrorismo, ao contrário da ideia equivocada de alguns, não se trata de um fenômeno contemporâneo mundial. Atividades ligadas a ele estiveram presentes em diversos Estados durante todo o século XX. No entanto, foi apenas no século XXI que o nível de preocupação dos Chefes de Estado, quanto à busca efetiva de combate a esse fenômeno, se desenvolveu consideravelmente.

Uma das principais motivações por trás de atos terroristas se refere à instalação do medo e insegurança na população, como forma de desestabilizar um governo, para que venha a realizar ou deixar de realizar algum ato ou série de atos específicos, seja no âmbito econômico, político, militar ou social.

Esse fenômeno passou a ser visto mundialmente de forma diferente após o dia 11/09/2001, marcado por uma série de ataques terroristas contra os Estados Unidos da América ${ }^{1}$ tornando essa data como um marco da história contemporânea do século XXI. Esse marco se deu não apenas pela magnitude dos ataques, nem por terem sido cometidos contra os EUA (país que sempre considerou como prioridade as defesas nacionais) e sim pelos alvos que foram escolhidos pelos terroristas. Eles representavam o centro financeiro do capitalismo e da inteligência militar. Esses ataques colocaram diversos países ocidentais capitalistas em alerta.

A preocupação, devido à ofensividade dos ataques cometidos, levou diversos países a refletirem sobre o presente nível de combate a possíveis ameaças terroristas futuras. Preocupações, essas, que acarretaram diversas medidas de

\footnotetext{
1 Os pontos atacados foram o World Trade Center e o Pentágono.
} 
retaliação proporcionais, por parte dos Estados. Entre tais medidas, destacam-se as novas legislações de combate ao terrorismo que passaram a ser implantadas em diversos países do mundo, principalmente da Europa. Legislações, que em certos casos (como o da França), conforme aqui será estudado, tendem a violar princípios fundamentais de proteção às pessoas humanas.

Nos EUA, por exemplo, a segurança se tornou quase que uma obsessão da população, tendo sido promulgado, logo após os ataques de 11 de setembro, o Patriot $\mathrm{Act}^{2}$. Essa legislação Americana aumentou significantemente o controle exercido pelo país nas fronteiras, instituindo novos programas que buscam o levantamento de informações pessoais, além de permitir um maior controle, das autoridades policiais, durante os interrogatórios de suspeitos.

Para os Franceses, a preocupação com a segurança também se tornou uma questão de grande relevância, tendo sido um dos principais temas abordados durante a corrida presidencial de 2002, ocasião em que o então presidente Nicola Sarkozy foi eleito, usando um discurso totalmente voltado para a segurança. A população Francesa passou a exigir a implantação de políticas efetivas de combate ao terrorismo, na busca de amenizar o crescente nível de insegurança que se desenvolvia no país.

Defensores de uma legislação mais rígida aproveitaram esse momento de insegurança para desenvolver as suas teses e argumentações de que Estados Democráticos possuem, devido a sua própria natureza, maiores dificuldades para implantar políticas eficientes de combate ao terrorismo, por se tratar de Estados garantidores de um vasto leque de direitos considerados fundamentais. Nessa óptica, Estados que possuem muitas garantias tenderiam a facilitar a execução de ações relacionadas ao terrorismo.

Entre esses direitos fundamentais que, supostamente, facilitariam a manifestação de atos terroristas, deve-se destacar o direito de livre movimentação dentro do país (facilitando a entrada de possíveis grupos terroristas), o direito à liberdade de expressão (podendo ser utilizado como meio de disseminação de propagandas de ideias terroristas, principalmente através da Internet), o direito de reuniões (por facilitar a organização de tais associações) e o direito à vida privada (dificultando o monitoramento de certos grupos suspeitos pelas autoridades).

Sob essa óptica, será analisado o contexto histórico francês que levou à criação da lei antiterrorismo e porque ela é tão severa no combate ao terrorismo

2 Promulgado em 26 de Outubro de 2001. 
dentro do território francês, aproveitando para fazer uma análise dessa legislação com princípios fundamentais de proteção a garantias individuais. Bem com analisar em que passo se encontra o Brasil quanto à defesa do território no que pertine a ameaças terroristas.

\section{A FranÇA COMO BERÇO DOS DIREITOS HUMANOS E OS AVANÇOS NESSA SEARA NA ÓPTICA INTERNACIONAL}

É sabido que a Declaração dos Direitos do Homem e do Cidadão surgiu na França, elevando esse país a berço dos direitos humanos mundiais, com uma legislação ampla e particular. A Declaração estabelece uma abrangência desses direitos fundamentais para o mundo, quais as prerrogativas, direitos e deveres dos homens e dos cidadãos, não apenas lá, mas em todos os países, em uma defesa direta contra os abusos cometidos durante os vários séculos que antecederam a essa declaração.

Tentativa bem sucedida de estabelecer padrões globais para as várias civilizações, fruto de um estudo detalhado e das várias discussões sobre o tema. Renderam não apenas a Declaração, mas a própria noção de direitos humanos, qual a abrangência deles em todos os países e a abordagem que deveriam ter para que tal legislação pudesse fazer efeito e o homem pudesse ser respeitado por essa condição, a de ser humano, respeitando-se, assim, o direito natural, de onde todos os demais se originaram.

Porém, há que se fazer justiça. Antes de a Declaração entrar em vigor, ou sequer estar nos planos dos seus criadores, outras nações já possuíam textos de declarações traçando rumos para se tratar sobre os direitos humanos, tais como a da Inglaterra, precursora dos direitos individuais civis e políticos, quando o Rei João Sem Terra instituiu a Magna Carta, de 1215, e outros textos menores estabelecendo liberdades fundamentais do ser humano e posteriormente os Estados Unidos, com a sua Declaração de Independência, de 1776, imperando o individualismo do pensamento das Luzes, movimento ocorrido na França, antecessor da Declaração, onde imperava a liberdade em todas as suas formas.

Dessa forma, considerando-se o terreno fértil que a Declaração preparou em todo o mundo para a difusão desses direitos humanos, imprescindível uma abordagem histórica sobre ela.

\subsection{DEClaraÇão dos direitos do HOMEM E DO CIDADÃo}

As origens da Declaração remontam ao judaísmo, considerado raiz cristã, trazendo a noção de pessoa, quando o ser humano foi feito à imagem e semelhança de Deus, seguindo-se os preceitos de religiosidade e das leis supremas. Também 
a noção de direito e jurisprudência e um racionalismo jurídico, com exigência de interpretação da lei de modo a possibilitar o exercício das liberdades, dentro da seara cristã de defesa da vida, defendida pela Bíblia.

O berço das civilizações modernas se originou do Cristianismo, da noção de Deus como Ser Supremo, sendo, inclusive, citado no preâmbulo da Declaração, marcando a ruptura com o cristianismo e, ao mesmo tempo, uma certa espiritualidade, reconhecendo-se, outrossim, o valor sagrado da pessoa humana, sendo a dignidade da pessoa humana eterna como o próprio Deus e, de outra monta, a igualdade entre todos os cidadãos. Ora, se todos são a imagem de Deus, então todos serão iguais aos olhos dele e de todas as nações.

Logo após essa explanação, mais religiosa que propriamente histórica, cabe uma sucinta explicação sobre as fontes da Declaração, que remontam à filosofia imperante na época, com as obras de Montesquieu (O espírito das Leis - 1748) e Rousseau (Do Contrato Social - 1762), e suas modernas teorias sobre a separação dos poderes e a lei como expressão da vontade geral.

Para Rousseau a idéia fundamental é a de igualdade, onde os homens nascem livres e iguais, não havendo liberdade sem igualdade, e pela vontade geral se estabelecem os limites dessa igualdade, defendendo-se a lei como balizamento da sociedade.

Se os homens concordaram em deixar o estado de natureza, é porque eles pensavam encontrar na organização social vantagens superiores: a associação de todos os indivíduos em um corpo (o contrato social) garante melhor manutenção e melhor defesa contra as forças hostis da natureza. (ISRAEL, 2005, p. 74).

A partir do momento em que os homens resolvem se estabelecer em sociedade, é porque chegou o momento de dividirem as responsabilidades, não é apenas um ser humano tentando sobreviver e sim vários querendo delimitar seu espaço e buscando sua sobrevivência e a de sua família, tornando as leis e regras imprescindíveis a que se estabeleça uma convivência harmoniosa entre esses seres.

Já Montesquieu, com sua teoria da separação dos poderes, onde imperava uma desconfiança com relação ao executivo, tornando necessário separarem-se as esferas de governo para possibilitar uma maior liberdade ao cidadão, inclusive de eleger representantes de seus interesses. Afirmava que sem separação de poderes não haveria constituição forte o bastante para controlar o rumo da vida social.

Uma constituição entendida como o objetivo de proteção da liberdade pressupõe duas condições: a separação dos poderes e a garantia dos direitos. A garantia dos direitos pressupõe a existência de uma hierarquia das normas, o que, na França, se realiza no âmbito constitucional, pelo guardião da Constituição que é, hoje, o Conselho Constitucional. 
[....] Garantia dos direitos e separação dos poderes são as condições de existência da Constituição. (ISRAEL, 2005, p. 79).

Dessa forma, foram plantadas as bases do maior compêndio de proteção aos direitos humanos previstos até hoje, o primeiro texto geral de direito positivo relativo às liberdades, imposto em 26 de agosto de 1789 , respeitado por todas as nações do mundo e adotada pela Assembléia Geral da ONU, em forma de resolução em 16 de dezembro de 1966. Compêndio esse que deu origem a tantas outras declarações no mesmo aspecto, ao redor do mundo.

Trata-se de uma declaração que é um ato recognitivo, sendo os direitos nela constantes declarados, ou seja, constatados ou reconhecidos e aceitos como tal. É também um ato positivo que deve convencer e não apenas enunciar, impondo uma obediência intrínseca a esse texto, declarando direitos naturais do ser humano.

O próprio preâmbulo da Declaração reconhece os direitos humanos como essenciais a essa qualidade, afirmando-se a existência de direitos individuais anteriores e superiores ao Estado:

Os representantes do povo francês, reunidos em Assembléia Nacional, tendo em vista que a ignorância, o esquecimento ou o desprezo dos direitos do homem são as únicas causas dos males públicos e da corrupção dos Governos, resolveram declarar solenemente os direitos naturais, inalienáveis e sagrados do homem, a fim de que esta declaração, sempre presente em todos os membros do corpo social, lhes lembre permanentemente seus direitos e seus deveres; a fim de que os atos do Poder Legislativo e do Poder Executivo, podendo ser a qualquer momento comparados com a finalidade de toda a instituição política, sejam por isso mais respeitados; a fim de que as reivindicações dos cidadãos, doravante fundadas em princípios simples e incontestáveis, se dirijam sempre à conservação da Constituição e à felicidade geral.

Em razão disto, a Assembléia Nacional reconhece e declara, na presença e sob a égide do Ser Supremo, os seguintes direitos do homem e do cidadão:

Conclui-se que a Declaração, no seu início reconhece o ser humano em sua essência e todas as regras que ela enuncia a partir daí tem o mesmo claro objetivo, respeitar o cidadão, dar a ele liberdade de agir e igualá-lo em todas as suas condições humanas.

Cabe aqui mencionar o art. $9^{\circ}$, da Declaração, enunciando: "Todo acusado é considerado inocente até ser declarado culpado e, se julgar indispensável prendêlo, todo o rigor desnecessário à guarda da sua pessoa deverá ser severamente 
reprimido pela lei". Ou seja, a lei protege aquele que é condenado de maus tratos e defende que deve existir um julgamento justo para que se prive a liberdade do ser humano.

A Declaração tem por características: a universalidade, o individualismo e a abstração, sendo características dos direitos naturais o fato de serem sagrados (aqui se evocando novamente a religiosidade), invioláveis e imprescritíveis (ou seja, não desaparecem e nem se invalidam pelo decurso de tempo).

O estopim dessa Declaração acontece com o advento das respectivas Constituições de 1946 e 1958, com a reafirmação dos princípios insculpidos no texto de proteção aos direitos humanos, nesta última constando em esparsos momentos do texto da Lei Maior.

Certo é que, a partir da Declaração dos Direitos do Homem e do Cidadão outras tantas declarações surgiram, sendo a mais importante a Convenção Européia para a Proteção dos Direitos Humanos:

Esse período será marcado simultaneamente pela extensão do reconhecimento dos direitos do homem (direitos de 1789, posteriormente a extensão a direitos novos) e pela contestação teórica e prática da concepção clássica (contestação do direito natural pelos positivistas: contestação marxista pelos regimes totalitários). (ISRAEL, 2005, p. 103).

Desse modo, não se pode falar em direitos humanos sem remeter à França e sua célebre Declaração dos Direitos do Homem e do Cidadão.

Imprescindível essa análise histórica para que se entenda como uma nação tão preocupada com os direitos humanos é capaz de instituir uma lei agressora desses mesmo direitos como o é a Lei Antiterrorismo que visa combater esse tipo de infração, e quais as razões históricas que levaram a implantação dessa lei.

\section{O Ataque a Paris em 2004 e o terrorismo sob uma NOVA PERSPECTIVA NA FRANÇA}

A explosão em Paris, no ano de 2004, próximo à embaixada da Indonésia, foi o primeiro ataque terrorista contra a França durante o interregno de oito anos. Esse ataque fez com que, ainda no ano de 2004, o terrorismo ganhasse maior destaque no país. O seu status foi elevado ao chamado chantier national, acarretando a priorização de esforços nacionais para que ataques como o ocorrido em Paris não viessem a se repetir. Esse novo status obrigou todos os órgãos do governo a buscarem medidas efetivas a serem alcançadas, de combate ao terrorismo.

Uma dessas novas medidas desenvolvidas pela França, de combate a atividades terroristas, ocorreu através da criação de um novo sistema, de âmbito nacional, intitulado Vigipirate. Esse sistema consiste em um programa de alerta 
de segurança nacional, atuando por meio do desenvolvimento de novas medidas preventivas de combate ao terrorismo. Essas medidas se dão na forma da edição de normas de segurança a serem adotadas em metrôs, praças e outros locais públicos, bem como em áreas territoriais fronteiriças com outros países.

Outra medida encontrada, após os ataques de 2004, foi a melhoria na troca de informações entre órgãos e agências do governo competentes para combater o terrorismo. A legislação francesa, em seu vigente modelo, prevê que diversos órgãos, agindo de forma hierárquica, busquem a garantia de um ou mais objetivos. No âmbito de combate ao terrorismo, diversos são os órgãos que possuem alguma competência: DST (Polícia Federal), RG (Serviço Geral de Inteligência), DNAT (Divisão Nacional Anti-Terrorismo) e o DSGE (Serviço Externo de Inteligência) sendo este uma agência ligada ao Ministério de Defesa, possuindo, assim como os demais institutos mencionados, certo nível de competência.

No entanto, a problemática que existia não era quanto à busca de agências suficientes para combater o terrorismo, pois, conforme pôde-se notar, já se tratava de uma quantidade significativa. A dificuldade, na verdade, existia na coordenação de tais órgãos, que tinham dificuldades de trocar informações entre si. Assim, necessária era uma mudança, para que todas as agências competentes pudessem passar a atuar em conjunto, na busca de se atingir eficientemente um bem comum.

Essa mudança veio com a criação de um órgão intitulado UCLAT (Unidade de Coordenação Operacional Anti-Terrorismo), que teria a competência unicamente de coordenar todas as ações e coletas de informações dos demais institutos.

\section{LEGISLAÇÃO FRANCESA: COMBATE AO TERRORISMO OU AOS DIREITOS FUNDAMENTAIS?}

O sistema central Francês de combate ao terrorismo foi desenvolvido no ano de 1986, por meio da Lei 86-1020, de 9 de Setembro daquele ano. Foi por esse novo sistema que se introduziu a figura de um Tribunal competente ${ }^{3}$ para lidar com os processos específicos englobando todos os casos de terrorismo do país.

Porém, foi em 23 de Janeiro de 2006, por meio da Lei 2006-644, que diversas das previsões criminais ligadas ao terrorismo, previstas na legislação Francesa, foram severamente difundidas. Entre essas previsões, destaca-se a duplicação da penalidade, contida no art. 421-2-1 do Código Penal Francês, para aqueles que são considerados culpados de participação em grupos ou associações que visem desenvolver qualquer tipo de atividade considerada terrorista, que passou de 10

3 Popularmente conhecido como "14 Seção", localizado na cidade de Paris.

4 Popularmente conhecida como "Lei Sarkozy". 
para 20 anos de reclusão. Aumentou-se, também, a punição daqueles considerados "líderes" de tais grupos, de 20 para 30 anos de reclusão.

Diversas são as críticas que vem sendo realizadas por entidades protetoras dos Direitos Humanos quanto às previsões contidas na vigente legislação Francesa de combate ao terrorismo. Entre as principais previsões criticadas, deve-se destacar:

- Suspeitos podem ficar sob custódia da polícia por 4 dias, ou em certos casos até 6 dias, antes de serem oficialmente colocados sob investigação judicial (através da instauração de processo) ou liberados;

- Os suspeitos somente podem ter acesso a um advogado após estarem em custódia por 3 dias. Quando o acesso finalmente é permitido, o tempo máximo da visita limita-se à 30 minutos;

- Aos advogados, no momento da visita a seu cliente, são disponibilizadas pouquíssimas informações sobre o caso, não tendo acesso a qualquer pasta ou arquivo sobre o mesmo;

- Suspeitos têm sido vítimas de interrogatórios constantes, muitas vezes de forma opressiva, e sem a presença de advogado;

- Os policiais não têm a obrigação legal, em caso de suspeitos de associação ao terrorismo, de informar ao suspeito o seu direito de permanecer em silêncio.

Um dos maiores problemas, da vigente lei Francesa Anti-Terrorismo, estaria na ampla definição de association de malfaiteurs en relation avec une enterprise terroriste. Inicialmente tipificado como conduta criminosa em 1996, essa tipificação prevê que, após se verificar a existência de alguma possível associação do indivíduo com atividades terroristas, as autoridades podem agir de forma preventiva, através da utilização de diversos atos severos, conforme já mencionado, na busca de um combate eficaz ao terrorismo, antes que venha a se concretizar.

Outrossim, o problema reside no fato de que a atual abrangência, prevista na lei, permite que uma pessoa seja detida sem ter realizado qualquer tipo de ato visando o planejamento de terror, mas que, devido à ampla possibilidade de interpretação da lei, o mesmo poderá ser enquadrado no crime de association de malfaiteurs ${ }^{5}$.

Importante esclarecer, também, o motivo da intensa severidade contida na discutida legislação Francesa de Anti-Terrorismo (Lei 2006-64). A lei foi elaborada após o atentado terrorista de Londres em 2005, ou seja, em tempos nos quais a Europa, principalmente a França, encontrava-se em um período de grande receio e a população clamava por segurança e punição àqueles envolvidos.

\footnotetext{
5 Previsão introduzida no Ordenamento Jurídico Francês pela Lei 96-647, de 22 de Julho de 1996.
} 
Assim, na França tem sido, constantemente, utilizado a vaga expressão de "ofensa por associação ao terrorismo" de forma abusiva, detendo um grande número de pessoas de forma arbitrária, com poucas provas de qualquer possível envolvimento da pessoa em tais ações. Devido a uma ausência de delimitação por parte da legislação, pessoas inocentes são constantemente enquadradas nessa previsão. Comprovando essa predominância de pessoas detidas, um estudo intitulado Preempting Justice: Counterterrorism Laws and Procedures in France da Organização Human Rights Watch (2008, on line) afirma que:

The vast majority of terrorism suspects are detained and prosecuted on this charge. According to government statistics, 300 of the 358 individuals in prison for terrorism offenses in September 2005 - both convicted and those awaiting trial - had been charged with association de malfaiteurs in relation to a terrorist undertaking.

Oficiais Franceses defendem a presença da flexibilidade dada pela legislação, sob o argumento de que o atual modelo permite aos oficiais atuar de uma forma mais efetiva quanto ao combate ao terrorismo. Sabe-se, porém, que um excesso de flexibilidade na interpretação de normas, em qualquer Ordenamento Jurídico, é o primeiro passo rumo a futuras injustiças e arbitrariedades.

Outro problema do atual sistema ocorre pelo fato de que muitas informações levadas em consideração em processos, contra suspeitos de association de malfaiteurs, são fruto de investigações conduzidas em outros países. Países, esses, que, muitas vezes, possuem poucas experiências ou pouco material humano para conduzir investigações precisas sobre o tema. Inclusive, existem alegações de que informações podem ser levadas em consideração, pelas autoridades Francesas, apesar de terem sido conseguidas em outros países pela prática de tortura. $\mathrm{O}$ mesmo estudo da Organização Human Rights Watch (2008, on line) apregoa:

The use of evidence obtained from third countries where torture and ill-treatment are routine raises particular concerns, including about the nature of cooperation between intelligence services in France and those countries. Some defendants in France who credibly allege they were tortured in third countries into confessing have successfully had the confessions excluded as evidence.

Observa-se, assim, uma grande incoerência na França, um país ativo no plano internacional quanto a busca pela concretização dos Direitos Fundamentais, em aceitar tal espécie de prova.

Afinal, a legislação Francesa de combate ao terrorismo deveria coadunar com as leis e tratados internacionais, assinados pelo país, de proteção aos Direitos Humanos, algo que se torna visualmente inexistente no atual modelo. Essa abrangência, quanto à interpretação contida na legislação, tem acarretado violações aos direitos dos acusados de terem um julgamento justo. A possibilidade de interpretação da association de malfaiteurs permite que pessoas consideradas suspeitas sejam detidas com poucas, ou até nenhuma, prova concreta de associação 
com atividades terroristas. Inclusive, na prática, uma técnica que vem sendo utilizada pelas autoridades é a de deter grandes quantidades de pessoas, na espera de que alguns deles possam vir a ter, ou vir a conhecer alguém que tenha, alguma informação considerada relevante para comprovar uma possível ligação de um terceiro com atividades terroristas.

Portanto, a ausência de uma definição precisa do termo association de malfaiteurs permite que pessoas sejam nela enquadradas e, posteriormente, até condenadas, apesar de poucas evidências comprovarem sua associação com atividades terroristas. Percebe-se que, na prática, basta que uma pessoa conheça outra ou dividam interesses similares, sejam esses interesses políticos ou religiosos, para que possam vir a ser considerados como suspeitos de associação ao terrorismo.

\section{UMA ANÁLISE JURÍDICO-PENAL DA LEGISLAÇÃO FRANCESA DE COMBATE AO TERRORISMO E DOS PRINCÍPIOS POR ELA VIOLADOS}

Em uma incessante busca para conseguir formas eficientes de combate ao terrorismo, a França tem realizado prisões e processado pessoas por estarem enquadradas na abrangente previsão de suspeitos de associação ao terrorismo, indo diretamente de encontro aos procedimentos internacionais e princípios basilares do sistema criminal e da garantia dos direitos fundamentais.

Dessa forma, imperioso iniciar destacando a violação ao princípio da presunção de inocência ${ }^{6}$. Esse princípio tem o seu marco histórico durante o Iluminismo, quando surgiu a necessidade de medidas prevendo a possibilidade de resistência ao sistema penal inquisitório existente, visando uma eficaz proteção do cidadão pelo Estado contra as possíveis arbitrariedades que tendiam a acontecer, em uma época onde se presumia a culpabilidade. Sua positivação nasce, ironicamente, durante a Revolução Francesa, merecendo previsão expressa no art. $9^{\circ}$ da Declaração dos Direitos do Homem e do Cidadão 7 , de 1789: "Todo o homem é considerado inocente, até o momento em que, reconhecido como culpado, se julgar indispensável a sua prisão: todo o rigor desnecessário, empregado para efetuar, deve ser severamente reprimido pela lei.

Portanto, observa-se ser um princípio que permite ao acusado ser tratado com a máxima dignidade possível, bem como ter respeitado seu direito à liberdade de locomoção. Sobre o tema, Eugênio Pacelli (2006, p. 32) afirma que:

6 Atualmente, esse princípio também tem sido referido, pelos doutrinadores, como Princípio do Estado de Inocência.

Tendo sido posteriormente reiterado no art. 26, da Declaração Americana de Direitos e Deveres, bem como no art. 11, da Declaração Universal dos Direitos Humanos. 
[....] situação jurídica de inocência, impõe ao Poder Público a observância de duas regras específicas em relação ao acusado: uma de tratamento, segundo a qual o réu, em nenhum momento do inter persecutório, pode sofrer restrições pessoais fundadas exclusivamente na possibilidade de condenação.

$[\ldots$.

No que lhe refere às regras de tratamento, o estado de inocência encontra efetiva aplicabilidade, sobretudo, no campo da prisão provisória, isso é, na custódia anterior ao trânsito em julgado, e no do instituto a que se convencionou chamar de "liberdade provisória".

Concordando com essa visão previamente destacada, Fernando Capez (2006, p. 44) vai mais longe, dividindo o Princípio da Presunção de Inocência em três aspectos, relevantes em qualquer tipo de prisão:

O princípio da presunção de inocência desdobra-se em três aspectos: a) no momento da instrução processual, como presunção legal relativa de nãoculpabilidade, invertendo-se o ônus da prova; b) no momento da avaliação da prova, valorando-a em favor do acusado quando houver dúvida; c) no curso do processo penal.

Verifica-se que, conforme a visão apontada pelo doutrinador, a legislação Francesa Antiterrorismo vai de encontro às duas primeiras fases, tanto no momento da instrução processual, ao deter indivíduos sem embasamentos justificáveis, quanto no momento da análise de provas, que será melhor avaliado a seguir, na forma de princípio próprio.

Outro princípio fundamental que vai de encontro à legislação de combate ao terrorismo, da França, é o princípio da humanidade da pena. Ele proíbe a prática de quaisquer atos de tortura, ou de tratamento desumano, na busca de uma eficaz defesa à integridade física do cidadão. Sua base internacional vem do art. V, da Declaração Universal dos Direitos Humanos" : "Ninguém será submetido à tortura nem a tratamentos ou punições cruéis, desumanos ou degradantes".

Coadunando com esse entendimento, de que o acusado deve ser sempre tratado como pessoa humana, destaca-se a visão de Jescheck (apud GOMES et al, 2007, p. 550) que afirma:

O princípio impõe que todas as relações humanas que o Direito Penal faz surgir no mais amplo sentido se regulem sobre a base de uma vinculação recíproca, de uma responsabilidade social frente ao deliquente, de uma livre disposição à ajuda e assistência sociais e de uma decidida vontade de recuperação do condenado [....] dentro dessas fronteiras, impostas pela natureza de sua missão, todas as relações humanas reguladas pelo Direito Penal devem estar presididas pelo princípio da humanidade.

8 Princípio previsto também no Pacto Internacional de Direitos Civis e Políticos, art. 10.1 e na Convenção Americana sobre Direitos Humanos, art. $5^{\circ}$. 
Observa-se que, conforme esse princípio, o Direito Penal deve se pautar pela benevolência, na busca de alcançar o bem estar, tanto da coletividade quanto dos acusados e condenados. A relevância desse princípio deve-se a sua nítida violação ao permitir formas de interrogatórios desumanas, conforme a previsão da legislação Francesa, permitindo que o suspeito fique sob custódia policial por até 3 dias antes de ter acesso a um advogado. Indivíduos relatam terem sido vítimas de tratamento de tortura durante as investigações, normalmente ocorrendo por meio da privação do sono, quando são feitos longos interrogatórios com duração de várias horas, impedindo, assim, o descanso do suspeito.

Outro relevante princípio violado é o da inadmissibilidade das provas obtidas ilicitamente. Esse princípio, fundado na necessidade de reconhecimento da proteção dos direitos humanos, serve, fundamentalmente, como um meio de proteção do jurisdicionando contra possíveis arbitrariedades que podem vir a ser cometidas pelo Poder Público.

Portanto, conforme esse princípio, é expressamente vedado, em um Estado Democrático de Direito, a aceitação de provas obtidas através de formas ilegais. Quanto a esse tema, Fernando Capez (2006, p. 33) ainda esclarece ser inadmissível tanto provas conseguidas por meios ilícitos quanto ilegítimos. No caso específico de provas conseguidas por meio de práticas de tortura (de maior relevância para o presente estudo) devem, tais provas, ser consideradas ilícitas, por se originarem de uma violação ao direito material:

Provas ilícitas são aquelas produzidas com violação a regras de direito material, ou seja, mediante a prática de algum ilícito penal, civil ou administrativo. Podemos citar como exemplos: a diligência de busca e apreensão sem prévia autorização judicial ou durante a noite: a confissão obtida mediante tortura. (grifou-se)

Observa-se que, tanto as provas consideradas ilícitas quanto as ilegítimas, devem ser processualmente vedadas, não podendo ser levadas em consideração como base para qualquer julgamento. Dessa forma, tanto o atual sistema de interrogatório Francês (contra os suspeitos de association de malfaiteurs) como a aceitação de provas obtidas em outros países, sem que haja uma avaliação de como essas provas foram obtidas, violam o princípio da inadmissibilidade da prova obtida ilicitamente.

Por fim, e talvez de mais nítida relevância ao tema central, o Princípio da Taxatividade. Esse princípio especifica que as condutas que o legislador acredita serem merecedoras de punição devem estar especificamente claras e suficientemente bem elaboradas no texto da lei, não podendo restar nenhuma dúvida, por parte daquele ao qual a norma se destina, quanto a sua interpretação.

Portanto, para que a lei possa obter sucesso no desempenho de sua função de motivar o comportamento humano, imprescindível que ela esteja disposta com clareza. René Ariel Dotti (2005, p. 60) esclarece: 
A doutrina esclarece que enquanto o princípio da anterioridade da lei penal se vincula às fontes do Direito Penal, o princípio da taxatividade preside a formulação técnica da lei penal e indica o dever imposto ao legislador de proceder, quando redige a norma, de maneira precisa na determinação dos tipos legais, para se saber, taxativamente, o que é penalmente ilícito e o que é penalmente admitido. (grifo original).

Para Guilherme de Souza Nucci (2006, p. 72) é vedada a elaboração de tipos penais que contenham expressões vagas ou ambíguas, podendo resultar em contraste de entendimentos:

A construção de tipos penais incriminadores dúbios e repletos de termos valorativos pode dar ensejo ao abuso do Estado na invasão da intimidade e da esfera de liberdade dos indivíduos. Alias, não fossem os tipos taxativos - limitativos, restritivos, precisos - de nada adiantaria adotar o princípio da legalidade ou da reserva legal. Este é um princípio decorrente, nitidamente, da legalidade.

Dessa forma, é óbvia a violação ao Princípio da Taxatividade na atual previsão Francesa de association de malfaiteurs, por não estar concretamente estabelecido em lei o que seria considerado uma violação a ela, o que tem levado a um significativo número (conforme apontado) de pessoas detidas sobre essa acusação. Uma disposição legal que contenha previsão de um crime de associação ao terrorismo deveria estar devidamente tipificada, de forma clara, sendo possível sua identificação por todos, pois somente dessa forma a lei poderá alcançar a sua função pedagógica de combater efetivamente o terrorismo.

\section{F. O COMBATE AO TERRORISMO NO BRASIL: ANTEPROJETOS DE LEI E SUAS PARTICULARIDADES}

O Brasil é considerado um país tranqüilo quando o assunto em pauta é o terrorismo. Não há registros de crimes de terrorismo dentro do território nacional, ou que sejam essencial e eminentemente atentados terroristas, não aqueles que se conhecem como terrorismo puro e sim formas mais alheias ao clássico conhecido, mas não menos perigosas.

Fala-se de atentados como: a invasão do Congresso Nacional pelo MLST, a destruição do Horto Florestal da Aracruz Celulose pela Via Campesina, os incêndios de ônibus no Rio e em São Paulo pelo crime organizado - Primeiro Comando da Capital (PCC) e Comando Vermelho (CV) -, a invasão da sede do Incra em Maceió pelo MST e a destruição do guichê da TAM por passageiros indignados com a crise do "apagão aéreo". Também o seqüestro do ônibus 174 no Rio, em 2000, e manifestações de apoio ao terrorista islâmico Osama Bin Laden, na visita de Bush a Brasília em 2005, podem ser considerados como atos terroristas, dependendo do ponto de vista. 
Em 12 de março de 2007, o Gabinete de Segurança Institucional entregou ao Ministério da Justiça um anteprojeto de lei que trata dos crimes terroristas e de seu financiamento. No entanto, esse anteprojeto não define o terrorismo, tarefa difícil até para a Organização das Nações Unidas - ONU, mas trata de definir quais seriam as práticas consideradas como de terrorismo, tendentes a serem enquadradas pela lei, deixando a cargo do Juiz, quando da apreciação do caso concreto dizer se tal prática se enquadra ou não nos ditames da lei.

$\mathrm{O}$ anteprojeto diz ainda quais seriam as práticas que ensejariam o enquadramento na futura lei: atentado à bomba, atentados nuclear ou radioativo, bioterrorismo, terrorismo químico, crimes contra pessoa e patrimônio, crimes contra pessoas internacionalmente protegidas (chefes de Estado, diplomatas e funcionários internacionais), financiamento ao terrorismo, crimes contra a segurança de aeronaves, embarcações e veículos de transporte coletivo, crimes contra a segurança de portos, aeroportos e estações de transporte coletivo, crimes contra a segurança de plataformas fixas (exploração de petróleo e gás), colaboração com o terrorismo, apologia ao terrorismo.

Se o anteprojeto virasse lei poderia ter sido utilizada para as práticas já anteriormente citadas, sendo que nenhuma delas representou, de fato, uma atitude terrorista, mas sim uma ameaça à nação como um todo. Algo que agride o Estado e as pessoas que dele fazem parte, pondo medo na população que sai às ruas já pensando que o pior pode acontecer. Se se pensar assim, a violência explícita dos grandes centros urbanos também é uma forma de terrorismo, porque, como diz o anteprojeto, a intenção da lei é punir crimes que tenham por finalidade infundir estado de pânico ou insegurança na sociedade, intimidar o Estado, organização internacional ou pessoa jurídica.

Dessa forma, não há que se falar na criação de uma lei antiterrorista no Brasil, posto que a legislação brasileira apta a combater tais práticas que seriam consideradas de terror é bastante ampla e aplicada para cada caso. Seria tornar o Brasil um alvo quando ele não o é, já que, como citado anteriormente, não há indícios de práticas terroristas no território nacional, pelo menos não como aquelas que se observa em países como Estados Unidos, França ou Inglaterra.

O que se tem no país é uma guerra entre Estado e Violência, onde impera o receio, mas não sem uma preocupação do Poder Público em punir essas práticas que trazem insegurança à população, que intimidam até as autoridades acostumadas a combater práticas violentas.

$\mathrm{O}$ anteprojeto virou um projeto de lei que seguiu para análise em uma das Casas do Congresso Nacional, porém, em virtude das críticas recebidas e depois de um ano de intensos estudos o projeto não foi aprovado e não virou lei, sem data para votação.

As grandes críticas em torno desse projeto são: primeiro, a desnecessidade dela para o território nacional, que não sofre ameaças terroristas; segundo, a existência de uma legislação apta a combater tais práticas e terceiro que seria considerado exagero tipificar as práticas descritas acima como terroristas. 
Reside também a crítica sobre a discricionariedade de os juízes poderem decidir quais seriam os casos que se enquadrariam na lei e como seria a pena aplicada para esses crimes.

Desse modo, permanece a legislação brasileira para repudiá-lo, principalmente, no que concerne ao argumento de que uma lei como essa atingiria sobremaneira os movimentos sociais que seriam taxados de movimentos do terror sem, contudo, usarem o terrorismo para conseguir algum propósito.

Dessa forma, pode-se considerar uma decisão acertada, tendo-se em conta que o país não sofre ameaças terroristas e caso venha a sofrer a legislação já é bastante ampla para albergar esses tipos de crimes, dando liberdade para que os movimentos sociais possam continuar defendendo suas causas sem sofrer qualquer tipo de ameaça ou coação.

\section{Considerações Finais}

A França é mundialmente conhecida como "berço dos direitos humanos". Reconhecimento esse advindo de diversas conquistas históricas asseguradas por esse Estado, zelador de uma eficaz concretização dos direitos fundamentais. Devido a isso, aparenta ser um grande passo para trás sua vigente legislação de combate ao terrorismo.

Portanto, acredita-se que, para a França fazes jus ao seu reconhecimento internacional, deve-se questionar a legitimidade de sua lei antiterrorismo, refletindo-se sobre suas atuais previsões.

Entre suas previsões, que precisam ser repensadas, destaca-se o reconhecimento da necessidade de que os suspeitos detidos possam ter acesso a um advogado a partir do momento de sua detenção, e não apenas 3 dias após o início dos interrogatórios, devendo também permitir a presença de seu representante legal no decorrer das investigações. Imprescindível, também, garantir a qualquer informação conseguida em outro país, principalmente naqueles onde a prática de tortura policial é corriqueira, que sua fundamentação seja devidamente analisada pela polícia Francesa, não devendo tais informações serem o suficiente para o enquadramento do cidadão como suspeito de associação ao terrorismo.

Por último, e talvez o ponto que mais clama por mudança, deve-se positivar um rol taxativo de atitudes que possam levar alguém a ser judicialmente acusado de association de malfaiteurs, sendo todas as atitudes, que estejam tipificadas na lei, apenas levadas em consideração com a presença de provas sólidas comprovando o envolvimento do indivíduo nas práticas terroristas. Essa necessidade reside no fato de que a não tipificação de tais atitudes pode levar, sobre o pretexto de um combate ao terrorismo, uma série de afrontas aos direitos e liberdades fundamentais nos quais o próprio Ordenamento Jurídico Francês se baseia. 


\section{REFERÊNCIAS}

BONAVIDES, Paulo. Curso de Direito Constitucional. 18. ed. São Paulo: Malheiros, 2007.

CAPEZ, Fernando. Curso de Processo Penal. 13. ed. São Paulo: Saraiva, 2006. DOTTI, René Ariel. Curso de Direito Penal. 2. ed. São Paulo: Forense, 2005.

FERREIRA FILHO, Manoel Gonçalves. Curso de Direito Constitucional. 33. ed. São Paulo: Saraiva, 2007.

GOMES, Luiz Flávio et al. Direito Penal: Introdução e Princípios Fundamentais. São Paulo: Revista dos Tribunais, 2007.

HERKENHOFF, João Baptista. Curso de Direitos Humanos. São Paulo: Acadêmica, 1994.

ISRAEL, Jean-Jacques [Tradução: Carlos Sousa]. Direito das Liberdades Fundamentais. São Paulo: Manole, 2005.

JESUS, Damásio E. de. Direito Penal: Parte Geral. 28. ed. São Paulo: Saraiva, 2006.

MIRABETE, Julio Fabrini. Processo Penal. 18. ed. São Paulo: Atlas, 2006.

MORAES, Alexandre de. Constituição do Brasil Interpretada. 5. ed. São Paulo: Atlas, 2005.

. Direitos Humanos Fundamentais. 6. ed. São Paulo: Atlas, 2005.

NUCCI, Guilherme de Souza. Manual de Direito Penal. 2. ed. São Paulo: Revista dos Tribunais, 2006.

OLIVEIRA, Eugênio Pacelli. Curso de Processo Penal. 6. ed. São Paulo: Del Rey, 2006.

PREEMPTING Justice: Counterterrorism Laws and Procedures in France. Human Rights Watch. Nova York, jul. 2008. Disponível em: <http://www.hrw.org/sites/ default/files/reports/france708_1.pdf>. Acesso em: 05 maio 2009.

RANGEL, Paulo. Direito Processual Penal. 11. ed. São Paulo: Lumen Juris, 2006.

RIVERO, Jean; MOUTOUH, Hugues [Tradução: Maria Ermantina de Almeida Prado Galvão]. Liberdades Públicas. São Paulo: Martins Fontes, 2006.

RODRIGUES, Alex. Lei antiterrorismo vai permitir criminalização de movimentos sociais, acusa fórum de direitos humanos. Agência Brasil. Brasília, mar. 2007. Disponível em: <http://www.agenciabrasil.gov.br/noticias/2007/03/26/ materia.2007-03-26.8657385656/view>. Acesso em: 05 maio 2009. 
.. Anteprojeto de lei contra terrorismo só será aplicado em casos extremos, avalia comandante. Agência Brasil. Brasília, mar. 2007. Disponível em: $<$ http:// www.agenciabrasil.gov.br/noticias/2007/03/26/materia.2007-03-26.8657385656/ view>. Acesso em: 05 mai. 2009.

. Governo estuda anteprojeto de lei contra o terrorismo. Agência Brasil. Brasília, mar. 2007. Disponível em: <http://www.agenciabrasil.gov.br/ noticias/2007/03/12/materia.2007-03-12.0924530635/view>. Acesso em: 05 maio 2009.

;. Juízes terão de interpretar conceito de terrorismo para aplicar futura lei. Agência Brasil. Brasília, mar. 2007. Disponível em: <http://www.agenciabrasil. gov.br/noticias/2007/03/12/materia.2007-03-12.0924530635/view>. Acesso em: 05 maio 2009.

TAVARES, André Ramos. Curso de Direito Constitucional. 6. ed. São Paulo: Saraiva, 2008.

WOLOSZYN, André Luis. O Brasil desiste da lei antiterror. Agência Brasileira de Inteligência - Abin. São Paulo, dez. 2007. Disponível em: <http://www.abin. gov.br/modules/articles/article.php?id=1619>. Acesso em: 05 maio 2009.

\section{ANTI-TERRORISM LAW IN FRANCE AND HUMAN RIGHTS}

Abstract: The present paper analyses the French counter-terrorism legislation, under the perspective of the fundamental principles violated by it, also considering the fact that France is knowingly world-wide as the cradle of human rights. It also focuses on how such a developed society, which is responsible for the creation of the Declaration of Rights of the Man and the Citizen, in 1789, could have approved a counter-terrorism legislation that violates such human rights. It is also traced here a comparative perspective of the French counter-terrorism legislation with the current Brazilian legislation.

Keywords: French Anti-Terrorism Law. Human Rights. Brazilian Anti-Terrorism Legislation. 